\title{
Mild cognitive impairment in different functional domains and incident Alzheimer's disease
}

\author{
N T Aggarwal, R S Wilson, T L Beck, J L Bienias, D A Bennett
}

J Neurol Neurosurg Psychiatry 2005;76:1479-1484. doi: 10.1136/jnnp.2004.053561

See end of article for authors' affiliations .....................

Correspondence to: Dr Neelum T Aggarwal, Rush Alzheimer's Disease Center, Rush University Medical Center, Armour Academic Center, $600 \mathrm{~S}$ Paulina, Suite 1038 , Chicago, IL 60612, USA; neelum_t_aggarwal@rsh. net

Received

8 September 2004

Revised version received

14 January 2005

Accepted

15 February 2005

Background: Little is known about factors that predict transition from mild cognitive impairment to Alzheimer's disease (AD).

Objective: To examine the relation of impairment in different cognitive systems to risk of developing AD in persons with mild cognitive impairment.

Methods: Participants are 218 older Catholic clergy members from the Religious Orders Study. At baseline, they met criteria for mild cognitive impairment based on a uniform clinical evaluation that included detailed cognitive testing. Evaluations were repeated annually for up to 10 years. Analyses were controlled for age, sex, and education.

Results: Eighty two persons (37.6\%) developed AD. In separate analyses, episodic memory, semantic memory, working memory, and perceptual speed, but not visuospatial ability, were associated with risk of $A D$, but when analysed together only episodic memory and perceptual speed were associated with $A D$ incidence, with the effect for episodic memory especially strong. Overall, those with impaired episodic memory were more than twice as likely to develop $A D$ as those with impairment in other cognitive domains (relative risk $(R R)=2.45 ; 95 \%$ confidence interval $(C I): 1.53$ to 3.92), and they experienced more rapid cognitive decline. Lower episodic memory performance was associated with increased risk of AD throughout the observation period, whereas impairment in other cognitive domains was primarily associated with risk during the following year but not thereafter.

Conclusion: Among persons with mild cognitive impairment, episodic memory impairment is associated with a substantial and persistent elevation in risk of developing $A D$ compared to impairment in other cognitive systems.

A mong older persons, those with mild cognitive impairment are known to be at increased risk of developing Alzheimer's disease $(\mathrm{AD})$ compared to older persons without discernable cognitive impairment. ${ }^{1-3}$ Older persons with mild cognitive impairment, variously defined, ${ }^{1}{ }^{3-5}$ are a heterogeneous group; however, some subsequently develop dementia, but a substantial proportion do not. The factors contributing to these different outcomes are not well understood.

Several prospective studies of people with mild cognitive impairment have examined the relation of level and type of cognitive impairment to risk of developing dementia and $\mathrm{AD}$, with mixed results. Thus, severity of impairment in global cognition, as measured by the Mini-Mental State Examination ${ }^{6}$ or Dementia Rating Scale, ${ }^{7}$ has been associated with risk of $\mathrm{AD}$ in some studies, ${ }^{89}$ but the effect has been limited to a subset of items ${ }^{10}{ }^{11}$ or been absent ${ }^{12}{ }^{13}$ in other studies. Because impaired episodic memory is an early and defining feature of $\mathrm{AD}$, some definitions of mild cognitive impairment are based primarily or exclusively on memory impairment. ${ }^{421415}$ Whether impairment in memory predicts subsequent dementia better than impairment in some other form of cognition is uncertain, however. In persons with mild cognitive impairment, memory test performance has been inversely associated with risk of developing $\mathrm{AD}$ in some studies ${ }^{10141617}$ but not in others. ${ }^{12} 1318$ One reason for these inconsistent findings may be that the ability of level of cognition to predict disease risk declines with the passage of time, but prior studies have not examined this issue to our knowledge. In addition, knowledge of the relation of cognitive function in domains other than episodic memory to risk of $\mathrm{AD}$ is limited because few large prospective studies have assessed multiple cognitive systems in people with mild cognitive impairment.

In this paper, we use data from the Religious Orders Study ${ }^{19}$ to examine how impairment in different cognitive domains is related to incident AD. Participants are older Catholic nuns, priests, and brothers with mild cognitive impairment who had structured annual clinical evaluations for up to 10 years. At baseline, they completed a battery of cognitive tests from which previously established summary measures of episodic memory and four other cognitive domains were derived. We first examined the differential association of level of function in several cognitive domains with risk of developing $\mathrm{AD}$ at any follow up point in a series of accelerated failure models. We then assessed the persistence of the risk associated with function in each cognitive domain in a series of logistic regression models with disease incidence at varying follow up durations as the outcomes.

\section{METHODS}

\section{Participants}

All participants are from the Religious Orders Study which involves annual clinical evaluations and brain donation at death. It was approved by the Institutional Review Board of Rush University Medical Center.

Clinical evaluations began in January of 1994 and are continuing. At the time of these analyses, 995 persons had completed the baseline clinical evaluation. Of these, 79 met criteria for dementia, 674 had no cognitive impairment, and

Abbreviations: $A D$, Alzheimer's disease; $\mathrm{Cl}$, confidence interval; NINCDS/ADRDA, National Institute of Neurological Communicative Disorders and Stroke and the Alzheimer's Disease and Related Disorders Association 
242 met criteria for mild cognitive impairment, as described below. Of those with mild cognitive impairment, eight died before the first follow up evaluation and 11 had not yet reached their first follow up date at the time of these analyses. Of the remaining 223 persons, 218 (97.8\%) participated in at least one follow up evaluation, with a mean of 6.1 evaluations per individual (because the study has ongoing enrolment, the number of evaluations ranged from 2 to 10). All analyses are based on this group. They had a mean (SD) age of 78.0 (7.1) years, a mean (SD) of 17.7 (3.2) years of education, and a mean (SD) Mini-Mental State Examination score of 27.4 (1.9) at baseline; $70.6 \%$ were women and $80.3 \%$ were white and non-Hispanic.

\section{Clinical evaluation}

At baseline, each participant underwent a uniform clinical evaluation that included a medical history, neurological examination, cognitive function assessment (see below), and review of brain scan if available. Clinical classification of cognitive impairment, dementia, and $\mathrm{AD}$ was accomplished in a three step process, as previously described. ${ }^{1}$ First, neuropsychological tests were administered by trained technicians and scored by a computer. Second, a board certified clinical neuropsychologist, blinded to the person's age, sex, and race, reviewed the results of all cognitive tests and data on education, occupation, sensory and motor deficits, and effort. Based on review of these data, the neuropsychologist rendered a clinical judgment regarding the presence of impairment in episodic memory and other cognitive domains. To maximise the consistency of these judgments, the neuropsychologist was provided with educationally adjusted cut off scores for determining impairment on 11 of the tests, as previously reported. ${ }^{1}$ Third, an experienced physician evaluated each participant and, based on review of all available data, classified each one with respect to $\mathrm{AD}$ and other common conditions of old age. The diagnosis of $\mathrm{AD}$ followed the criteria of the joint working group of the National Institute of Neurological Communicative Disorders and Stroke and the Alzheimer's Disease and Related Disorders Association (NINCDS/ ADRDA $).^{20}$ These criteria require a history of cognitive decline and impairment in at least two cognitive domains, one of which must be memory, to meet AD criteria.

There are no consensus criteria for the clinical classification of mild cognitive impairment. In this study, persons were designated as having mild cognitive impairment who were judged to have cognitive impairment by the neuropsychologist, but did not meet NINCDS/ADRDA criteria for dementia. These criteria for mild cognitive impairment have been used in many previous studies. ${ }^{121-24}$ In some analyses, we subdivided persons with mild cognitive impairment into those judged by the neuropsychologist to have episodic memory impairment, as described above, and those without impaired episodic memory.

\section{Assessment of cognitive function}

A total of 20 cognitive performance tests were administered as part of each evaluation. One test, the Mini-Mental State Examination, ${ }^{6}$ a measure of global cognition, was used for descriptive purposes, but not in analyses. Seven tests assessed episodic memory: immediate and delayed recall of the East Boston Story ${ }^{25} 26$ and Story A from Logical Memory, ${ }^{27}$ and Word List Memory, Recall and Recognition. ${ }^{28}$ Semantic memory was assessed with a 20 item version of the Boston Naming Test, ${ }^{29}$ a 15 item form of Extended Range Vocabulary,,$^{30}$ and a 20 item form of the National Adult Reading Test. ${ }^{31}$ There were four tests of working memory: Digit Ordering, ${ }^{32}$ Alpha Span, ${ }^{33}$ and Digit Span Forward and Digit Span Backward. ${ }^{27}$ Perceptual speed was assessed with the oral version of the Symbol Digit Modalities Test ${ }^{34}$ and Number Comparison, ${ }^{30}$ and visuospatial ability was evaluated with a 15 item version of Judgment of Line Orientation ${ }^{35}$ and a 17 item version of Standard Progressive Matrices. ${ }^{36}$

Composites of two or more tests were used in analyses to reduce measurement error in general and floor and ceiling artefacts in particular. Based in part on a factor analysis of the tests at baseline, ${ }^{26}$ we formed measures of episodic memory (based on seven tests), semantic memory (four tests), working memory (four tests), perceptual speed (two tests), and visuospatial ability (two tests). Raw scores on each component test were converted to $\mathrm{z}$ scores, using the baseline mean and standard deviation from all participants in the Religious Orders Study, and averaged to form the composite measures. Further information on the individual tests and on the derivation and psychometric properties of these composite measures is contained in previous publications..$^{26} 3738$

\section{Data analysis}

To assess the differential association of level of function in various cognitive systems with overall disease risk, we constructed a series of accelerated failure time models ${ }^{39}$ adjusted for age, sex, and education. The Weibull accelerated failure time model allows characterisation of relative risk ratios when the assumption of proportional hazards is not tenable, which was the situation with our data. We first constructed separate models for each composite cognitive measure and then analysed all five measures together, followed by a model contrasting those with and without impaired episodic memory.

We used mixed effects models ${ }^{40}$ to test whether rate of decline in each cognitive domain differed between persons with versus without episodic memory impairment. Each model had terms for time, the presence of episodic memory impairment, and their interaction plus terms to control for age, sex, and education. The interaction term indicates the additional decline per year associated with having impaired episodic memory at baseline. Further information on the use of mixed effects models with longitudinal cognitive data is published elsewhere. ${ }^{26}{ }^{41}$

To examine how the association of level of cognition with risk of $\mathrm{AD}$ changed with time, we divided those who developed $\mathrm{AD}$ into five subgroups of approximately equal size based on how soon the diagnosis was made following the baseline evaluation. Using these time categories, we then tested the association of each baseline cognitive measure with risk of developing $\mathrm{AD}$ within a given follow up period (for example, during the first year, during the second year, after 6 or more years) in a set of five separate logistic regression models adjusted for age, sex, and education.

Model assumptions were examined graphically and analytically, and found to be adequately met. Programming was done in SAS. ${ }^{42}$

\section{RESULTS}

\section{Level of function in different cognitive systems and} incidence of Alzheimer's disease

At baseline, the composite measure of episodic memory had a mean of -0.43 (SD 0.64, interquartile range 0.83 ); mean semantic memory score was -0.33 (SD 0.66, interquartile range 0.84 ); mean working memory score was -0.26 (SD 0.65, interquartile range 0.78); mean perceptual speed score was -0.35 (SD 0.79, interquartile range 1.02); and mean visuospatial ability score was -0.53 (SD 0.75, interquartile range 1.11).

During a mean of 5.1 years of follow up, 82 persons developed $\mathrm{AD}$, a rate of about $8 \%$ per year which is roughly consistent with previous research. ${ }^{43}{ }^{44}$ Three persons who 
developed other forms of dementia (that is, stroke, Parkinson's Disease, depression) were excluded from further analyses. We first examined the association of baseline level of function in each cognitive domain to disease incidence in separate accelerated failure models adjusted for age, sex, and education. In these analyses (left side of table 1), lower level of each function except visuospatial ability was related to increased risk of developing $\mathrm{AD}$, although the effect appeared considerably stronger for episodic memory compared to other functions.

We visually examined these associations by plotting the model based estimate of the cumulative hazard of developing $\mathrm{AD}$ for persons with high (75th percentile) and low (25th percentile) levels of function in each cognitive domain (fig l). The figure suggests that the risk of developing $\mathrm{AD}$ associated with a low episodic memory score was about twice the risk associated with having a low score in other cognitive domains.

To assess the independent contribution of each domain, we repeated the analysis with all five cognitive measures in the same model (right side of table 1). In this analysis, episodic memory and perceptual speed, but not the other cognitive measures, were related to disease incidence.

To further examine the differential risk associated with impairment of episodic memory compared to other cognitive domains, we divided participants into those with $(\mathrm{n}=126)$ and without $(\mathrm{n}=116)$ episodic memory impairment, based on review of all test data by a boarded clinical neuropsychologist, as described above. As shown in fig 2, which was based on this analysis, persons with episodic memory impairment were more than twice as likely to develop $\mathrm{AD}$ as persons with impairment in other cognitive domains (relative risk $(\mathrm{RR})=2.45 ; 95 \%$ confidence interval $(\mathrm{CI}): 1.53$ to 3.92 ).

Because clinical classification of $\mathrm{AD}$ can be difficult, we examined rate of cognitive decline, the primary clinical manifestation of the disease, in those with and without episodic memory impairment. In separate mixed effects models controlled for age, sex, and education, those with baseline episodic memory impairment declined more rapidly in semantic memory $(\mathrm{p}=0.027)$ and visuospatial ability $(p=0.007)$ than those with impairment in other cognitive systems, with no differences in the other cognitive domains (all $\mathrm{p}>0.150$ ).

\section{Persistence of $A D$ risk associated with level of function in different cognitive systems}

To evaluate how the relation of cognitive function to disease incidence changed with the passage of time, we divided those who developed $\mathrm{AD}$ into five subgroups: 26 people diagnosed at the first year follow up, 15 at year 2, 16 at year 3, 13 in years 4 and 5 combined, and 12 in year 6 or later. We then examined the relation of baseline score on each summary cognitive measure to disease incidence at each of these five follow up points in separate logistic regression models adjusted for age, sex, and education. The results of these analyses for episodic memory are shown at the top of table 2 .
Lower baseline episodic memory was associated with an increased risk of developing $\mathrm{AD}$ at the first and second year follow up evaluations and after 6 or more years of follow up, with similar trends at the intermediate follow up points. By contrast, lower levels of semantic memory, working memory, and perceptual speed were each associated with a higher risk of $\mathrm{AD}$ at the first year follow up point but relatively rarely thereafter, and visuospatial ability was unrelated to disease incidence at any follow up point.

\section{DISCUSSION}

We annually examined a group of more than 200 older persons with mild cognitive impairment for a mean of about 5 years. Among those with episodic memory impairment, risk of developing $\mathrm{AD}$ was stronger and more persistent, and cognition declined more rapidly, compared to those with impairment in other cognitive domains. The results suggest that risk of $\mathrm{AD}$ in mild cognitive impairment depends strongly on level of episodic memory.

The association between cognitive test performance in persons with mild cognitive impairment and subsequent risk of dementia and $\mathrm{AD}$ has been difficult to establish, as noted above. One issue is that sample sizes have often been small, with few studies of more than 100 participants, ${ }^{10141718}$ limiting the power to detect the associations of interest and the ability to control potentially confounding variables like age and education. In larger prospective studies that controlled for demographic variables, measures of episodic memory, ${ }^{14}{ }^{17}$ semantic memory, ${ }^{10}{ }^{17}$ working memory, ${ }^{14}$ and perceptual speed ${ }^{10}$ have been associated with disease risk, consistent with the results of this study.

Another uncertainty has been whether impairment in some cognitive domains predicts $\mathrm{AD}$ better than impairment in other domains among those with mild cognitive impairment. In this cohort, we found that the presence and severity of episodic memory impairment was generally more robustly related to risk of disease than the presence or severity of impairment in other cognitive domains. This effect may be due in part to memory impairment being a diagnostic criterion for AD. ${ }^{20}{ }^{45}$ However, persons with impaired episodic memory experienced more rapid cognitive decline than those with impairment in domains other than episodic memory. This observation plus neuroimaging evidence of structural ${ }^{46}$ and functional ${ }^{47}$ abnormalities in the medial region of the temporal lobe of persons with mild cognitive impairment suggest that the effect has a biological basis.

A novel feature of this study is that we examined predictive accuracy as a function of the time between cognitive testing and clinical classification of disease incidence. As expected, predictive accuracy tended to decline with the passage of time, likely reflecting the modest correlation between cognition measured at a single point in time and subsequent rate of change in cognition. ${ }^{26} 48$ Of interest, the association of episodic memory with $\mathrm{AD}$ risk attenuated relatively little during the observation period, whereas the association of semantic memory, working memory, and perceptual speed

Table 1 Relation of baseline level of function in different cognitive domains to risk of incident $A D^{*}$

\begin{tabular}{|c|c|c|c|c|c|c|c|c|}
\hline \multirow[b]{2}{*}{ Cognitive domain } & \multicolumn{4}{|c|}{ Separate models } & \multicolumn{4}{|l|}{ Single model } \\
\hline & Estimate (SE) & $\chi^{2}$ & $p$ & RR $(95 \% \mathrm{Cl})$ & Estimate (SE) & $\chi^{2}$ & $p$ & RR $(95 \% \mathrm{Cl})$ \\
\hline Episodic memory & $0.72(0.13)$ & 33.2 & $<0.001$ & $0.39(0.28$ to 0.54$)$ & $1.12(0.15)$ & 55.6 & $<0.001$ & $0.18(0.11$ to 0.28$)$ \\
\hline Semantic memory & $0.38(0.14)$ & 7.0 & 0.008 & $0.62(0.43$ to 0.88$)$ & $0.13(0.15)$ & 0.8 & 0.370 & $0.81(0.52$ to 1.28$)$ \\
\hline Working memory & $0.42(0.15)$ & 8.0 & 0.005 & $0.59(0.41$ to 0.85$)$ & $0.07(0.15)$ & 0.2 & 0.651 & 0.90 (0.57 to 1.42$)$ \\
\hline Perceptual memory & $0.43(0.12)$ & 12.2 & $<0.001$ & $0.57(0.42$ to 0.78$)$ & $0.36(0.12)$ & 8.3 & 0.004 & $0.58(0.40$ to 0.84$)$ \\
\hline Visuospatial ability & $-0.16(0.12)$ & 1.7 & 0.198 & $1.22(0.90$ to 1.66$)$ & $0.07(0.11)$ & 0.4 & 0.536 & 0.90 (0.63 to 1.27$)$ \\
\hline
\end{tabular}

*Estimated from accelerated failure models adjusted for age, sex, and education.

$\mathrm{Cl}$, confidence interval; $\mathrm{RR}$, relative risk. 

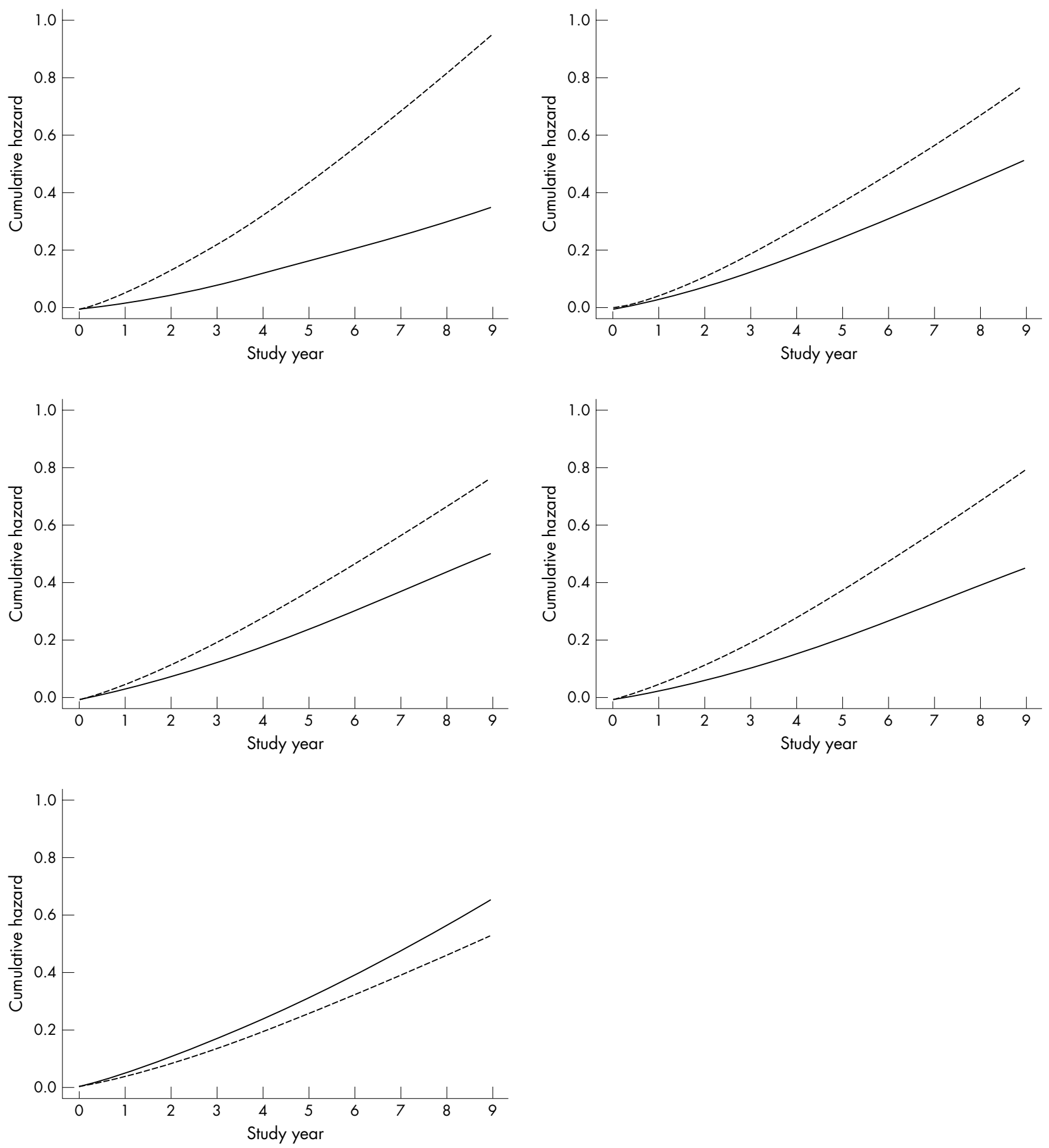

Figure 1 Cumulative hazard of developing $A D$ in those with cognitive scores at the 25th (dotted line) versus 75th (solid line) percentile in episodic memory (upper left), semantic memory (upper right), working memory (middle left), perceptual speed (middle right), and visuospatial ability (lower left).

with disease incidence was mainly confined to the first year or two of follow up, suggesting that low episodic memory performance is more likely to reflect functional decline than is low performance in other cognitive domains. An unexpected finding was that visuospatial ability, which has not been extensively studied in mild cognitive impairment, had no association with $\mathrm{AD}$ risk at any follow up point.

An obstacle to research progress in this area is the lack of agreement on what constitutes mild cognitive impairment. Classification of mild cognitive impairment in this study was based on criteria that have been widely used in previous research. ${ }^{11-24}$ These criteria have several important features.
First, they require evidence of cognitive impairment on performance testing so that persons with reported cognitive dysfunction or difficulty with activities of daily living in the absence of cognitive impairment are not included. Second, the criteria allow all older people to be classified as having dementia, mild cognitive impairment, or no cognitive impairment. Third, they do not assume that particular subtypes or dimensions of mild cognitive impairment are more important than others.

Confidence in these finding is strengthened by several factors. Clinical classification of mild cognitive impairment and $\mathrm{AD}$ was based on a uniform clinical evaluation and 


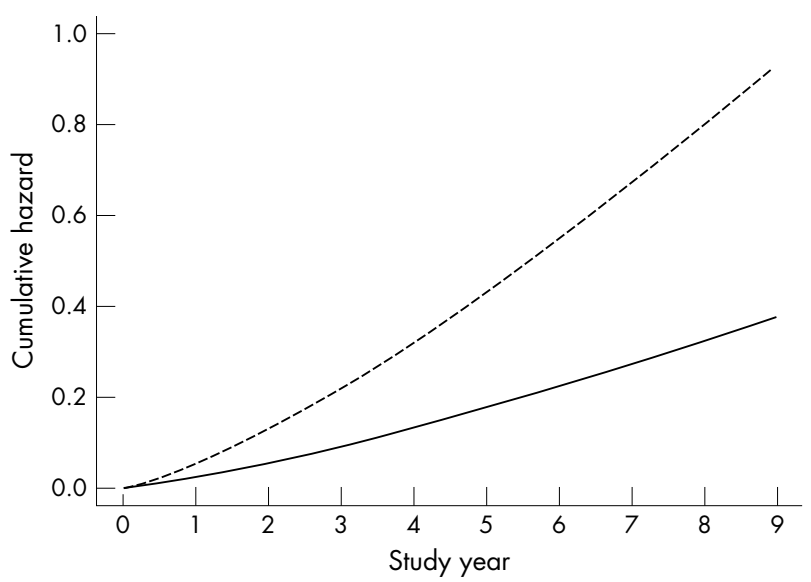

Figure 2 Cumulative hazard of developing $A D$ in those with impairment in episodic memory (dotted line) or in some other cognitive domain (solid line).

application of widely used criteria by experienced clinicians, and the effect of episodic memory impairment was observed for both clinically diagnosed $\mathrm{AD}$ and rate of cognitive decline, reducing the likelihood that diagnostic bias or imprecision affected results. The availability of more than 200 people with mild cognitive impairment with a mean of 5-6 years of follow up and high follow up participation enhanced our power to detect associations between cognitive test performance and disease incidence. Use of previously established composite measures of different cognitive systems allowed us to examine whether the association of cognition with disease risk varied across functional domains.

The main limitation of these findings is that they are based on a selected group of participants who differ in education and lifestyle from older persons in the United States population. Similar studies of more diverse groups of older people are needed. In addition, episodic memory was assessed exclusively with verbal tests. Whether these results will apply to episodic memory for non-verbal information is uncertain.

These findings have practical implications for clinicians who have older patients with mild cognitive impairment. Given evidence of episodic memory impairment, suspicion that the underlying condition is $\mathrm{AD}$ should remain high even if function in other cognitive domains is relatively preserved. Conversely, in the absence of impaired episodic memory, impairment in other cognitive domains is less likely to be an early sign of $\mathrm{AD}$.

\section{ACKNOWLEDGEMENTS}

The authors thank the hundreds of nuns, priests, and brothers from the following groups participating in the Religious Orders Study: archdiocesan priests, Chicago, IL, Dubuque, IA, and Milwaukee, WI; Benedictine monks, Lisle, IL and Collegeville, MN; Benedictine Sisters, Erie, PA; Benedictine Sisters of the Sacred Heart, Lisle, IL; Capuchins, Appleton, WI; Christian Brothers, Chicago, IL and Memphis, TN; diocesan priests, Gary, IN; Dominicans, River Forest, IL; Felician Sisters, Chicago, IL; Franciscan Handmaids of Mary, New York, NY; Franciscans, Chicago, IL; Holy Spirit Missionary Sisters, Techny, IL, Maryknolls, Los Altos, CA, and Maryknolls, NY; Norbertines, De Pere, WI; Oblate Sisters of Providence, Baltimore, MD; Passionists, Chicago, IL; Presentation Sisters, BVM, Dubuque, IA; Servites, Chicago, IL; Sinsinawa Dominican Sisters, Chicago, IL and Sinsinawa, WI; Sisters of Charity, BVM, Chicago, IL and Dubuque, IA; Sisters of the Holy Family, New Orleans, LA; Sisters of the Holy Family of Nazareth, Des Plaines, IL; Sisters of Mercy of the Americans, Chicago, IL, Aurora, IL, and Erie, PA; Sisters of St. Benedict, St. Cloud, MN and St. Joseph, MN; Sisters of St. Casimir, Chicago, IL; Sisters of St. Francis of Mary Immaculate, Joliet, IL; Sisters of St. Joseph of la Grange, LaGrange Park, IL; Society of
Table 2 Relation of baseline level of function in different cognitive domains to risk of developing incident $A D$ at different follow up periods*

\begin{tabular}{|c|c|c|c|}
\hline $\begin{array}{l}\text { Year AD } \\
\text { diagnosed }\end{array}$ & Cognitive domain & Odds ratio & $95 \% \mathrm{Cl}$ \\
\hline 1 & Episodic memory & 0.199 & 0.093 to 0.425 \\
\hline 2 & & 0.152 & 0.053 to 0.436 \\
\hline 3 & & 0.430 & 0.166 to 1.115 \\
\hline 4,5 & & 0.401 & 0.139 to 1.158 \\
\hline 6 or later & & 0.206 & 0.048 to 0.888 \\
\hline 1 & Semantic memory & 0.488 & 0.245 to 0.971 \\
\hline 2 & & 0.330 & 0.125 to 0.873 \\
\hline 3 & & 1.054 & 0.402 to 2.765 \\
\hline 4,5 & & 1.122 & 0.393 to 3.203 \\
\hline 6 or later & & 0.244 & 0.054 to 1.098 \\
\hline 1 & Working memory & 0.399 & 0.184 to 0.864 \\
\hline 2 & & 0.858 & 0.350 to 2.106 \\
\hline 3 & & 0.778 & 0.303 to 1.996 \\
\hline 4,5 & & 0.170 & 0.047 to 0.620 \\
\hline 6 or later & & 0.606 & 0.195 to 1.886 \\
\hline 1 & Perceptual speed & 0.402 & 0.217 to 0.745 \\
\hline 2 & & 0.561 & 0.254 to 1.238 \\
\hline 3 & & 0.747 & 0.303 to 1.845 \\
\hline 4,5 & & 0.549 & 0.228 to 1.324 \\
\hline 6 or later & & 0.602 & 0.193 to 1.881 \\
\hline 1 & Visuospatial ability & 1.054 & 0.584 to 1.903 \\
\hline 2 & & 1.323 & 0.639 to 2.740 \\
\hline 3 & & 1.450 & 0.636 to 3.307 \\
\hline 4,5 & & 1.005 & 0.418 to 2.417 \\
\hline 6 or later & & 1.177 & 0.394 to 3.518 \\
\hline
\end{tabular}

*From logistic regression models adjusted for age, sex, and education.

Divine Word, Techny, IL; Trappists, Gethsemane, KY and Peosta, IA; and Wheaten Franciscan Sisters, Wheaton, IL. They also thank Julie Bach, MSW and Tracy Colvin, MPH for coordinating the Religious Orders Study, George Dombrowski, MS and Greg Klein for data management, and Valerie J. Young for preparing the manuscript.

\section{Authors' affiliations}

N T Aggarwal, R S Wilson, D A Bennett, Rush Alzheimer's Disease Center, Rush University Medical Center, Chicago, IL, USA

T L Beck, J L Bienias, Rush Institute for Healthy Aging, Rush University Medical Center, Chicago, IL, USA

J L Bienias, Department of Internal Medicine, Rush University Medical Center, Chicago, IL, USA

This research was supported by National Institute on Aging grants R01 AG15819 and P30 AG10161.

Competing interests: none declared

\section{REFERENCES}

1 Bennett DA, Wilson RS, Schneider JA, et al. Natural history of mild cognitive impairment in older persons. Neurology 2002;59:198-205.

2 Larrieu S, Letenneur L, Orgogozo JM, et al. Incidence and outcome of mild cognitive impairment in a population-based prospective cohort. Neurology 2002;59:1594-9.

3 Tuokko H, Frerichs R, Graham J, et al. Five-year follow-up of cognitive impairment with no dementia. Arch Neurol 2003;60:577-82.

4 Petersen RC, Doody R, Kurz A, et al. Current concepts in mild cognitive impairment. Arch Neurol 2001;58:1985-92.

5 Luis CA, Loewenstein DA, Acevedo A, et al. Mild cognitive impairment: directions for future research. Neurology 2003;61:438-44.

6 Folstein MF, Folstein SE, McHugh PR. Mini-Mental State: a practical method for grading the mental state of patients for the clinician. J Psychiatr Res 1975; 12:189-98.

7 Mattis S. Dementia Rating Scale (DRS). Odessa, FL: Psychological Assessment Resources, 1988.

8 Visser PJ, Verhey FR, Ponds RW, et al. Course of objective memory impairment in non-demented subjects attending a memory clinic and predictors of outcome. Int J Geriatr Psychiatry 2000;15:363-72.

9 Jack CR, Petersen RC, Xu YC, et al. Prediction of AD with MRI-based hippocampal volume in mild cognitive impairment. Neurology 1999;52:1397-403.

10 Devanand DP, Folz M, Gorlyn M, et al. Questionable dementia: clinical course and predictors of outcome. J Am Geriatr Soc 1997;45:321-8.

11 Meyer JS, Xu G, Thornby J, et al. Longitudinal analysis of abnormal domains comprising mild cognitive impairment (MCl) during aging. J Neurol Sci 2002;201:19-25 
12 Bowen J, Teri L, Kukull W, et al. Progression to dementia in patients with isolated memory loss. Lancet 1997;349:763-5.

13 Petersen RC, Smith GE, Ivnik RJ, et al. Apolipoprotein E status as a predictor of the development of Alzheimer's disease in memory-impaired individuals. JAMA 1995;273:1274-8.

14 Tierney MC, Szalai JP, Snow WG, et al. Prediction of probable Alzheimer's disease in memory impaired patients: a prospective longitudinal study. Neurology 1996;46:661-5.

15 Lambon Ralph MA, Patterson K, Graham N, et al. Homogeneity and heterogeneity in mild cognitive impairment and Alzheimer's disease: a crosssectional and longitudinal study of 55 cases. Brain 2003;126:2350-62

16 Albert MA, Moss MB, Tanzi R, et al. Preclinical prediction of AD using neuropsychological tests. J Int Neuropscyhol Soc 2001;7:631-9.

17 Artero S, Tierney MC, Touchon J, et al. Prediction of transition from cognitive impairment to senile dementia: a prospective, longitudinal study. Acta Psychiatr Scand 2003;107:390-3.

18 Tian J, Bucks RS, Haworth J, et al. Neuropsychological prediction of conversion to dementia from questionable dementia: statistically significant but not yet clinically useful. J Neurol Neurosurg Psychiatry 2003;74:433-8.

19 Wilson RS, Bienias JL, Evans DA, et al. Religious Orders Study: overview and change in cognitive and motor speed. Aging Neuropsychol Cogn 2004;11:280-303.

20 McKhann G, Drachman D, Folstein M, et al. Clinical diagnosis of Alzheimer's disease: report of the NINCDS-ADRDA Work Group under the auspices of Department of Health and Human Services Task Force on Alzheimer's Disease. Neurology 1984;34:939-44.

21 Kordower J, Chu Y, Stebbins GT, et al. Loss and atrophy of layer II entorhinal cortex neurons in elderly people with mild cognitive impairment. Ann Neurol 2001;49:202-13.

22 Mitchell TW, Mufson EJ, Schneider JA, et al. Parahippocampal tau pathology in healthy aging, mild cognitive impairment and early Alzheimer's disease. Ann Neurol 2002;51:182-9.

23 Ghoshel N, Garcia-Sierra F, Wuu J, et al. Tau conformational changes correspond to impairment of episodic memory in mild cognitive impairment and Alzheimer's disease. Exp Neurol 2002;177:475-93.

24 Mufson EJ, Ma SY, Cochran EJ, et al. Loss of nucleus basalis neurons containing trkA immunoreactivity in individuals with mild cognitive impairment and early Alzheimer's disease. J Comp Neurol 2000;427:19-30.

25 Albert MS, Smith LA, Scherr PA, et al. Use of brief cognitive tests to identify individuals in the community with clinically diagnosed Alzheimer's disease. Int J Neurosci 1991;57:167-78.

26 Wilson RS, Beckett LA, Barnes LL, et al. Individual differences in rates of change in cognitive abilities of older persons. Psychol Aging 2002;17:179-93.

27 Wechsler D. Wechsler Memory Scale-Revised manual. San Antonio, TX: Psychological Corporation, 1987.

28 Welsh KA, Butters N, Mohs RC, et al. The Consortium to Establish a Registry for Alzheimer's Disease (CERAD). Part V. A normative study of the neuropsychological battery. Neurology 1994;44:609-14.
29 Kaplan EF, Goodglass H, Weintraub S. The Boston Naming Test, 2nd ed. Philadelphia: Lea \& Febiger, 1983.

30 Ekstrom RB, French JW, Harmen HH, et al. Manual for factor-referenced cognitive tests. Princeton, NJ: Educational Testing Service, 1976.

31 Nelson HE. National Adult Reading Test (NART) test manual. Windsor, UK: Nelson Publishing, 1982.

32 Cooper JA, Sager HJ, Jordan N, et al. Cognitive impairment in early, untreated Parkinson's disease and its relationship to motor disability. Brain $1991 ; 114: 2095-122$

33 Craik JIM. A functional account of age differences in memory. In: Klix E, Hagendorf $\mathrm{H}$, eds. Human memory and cognitive capabilities: mechanisms and performances. Amsterdam: Elsevier Science, 1986:409-22.

34 Smith A. Symbol Digit Modalities Test manual-revised. Los Angeles: Western Psychological Services, 1982.

35 Benton AL, Sivan AB, Hamsher K, et al. Contributions to neuropsychological assessment, 2nd ed. New York: Oxford University Press, 1994.

36 Raven JC, Court JH, Raven J. Manual for Raven's Progressive Matrices and Vocabulary Scales. Oxford: Oxford University Press, 1992.

37 Wilson RS, Mendes de Leon CF, Barnes LL, et al. Participation in cognitively stimulating activities and risk of incident Alzheimer's disease. JAMA 2002;287:742-8.

38 Wilson RS, Evans DA, Bienias JL, et al. Proneness to psychological distress is associated with risk of Alzheimer's disease. Neurology 2003;61:1479-85.

39 Carroll KJ. On the use and utility of the Weibull model in the analysis of survival data. Control Clin Trials 2003;24:682-701.

40 Laird N, Ware J. Random-effects models for longitudinal data. Biometrics 1982;38:963-73.

41 Wilson RS, Gilley DW, Bennett DA, et al. Person-specific paths of cognitive decline in Alzheimer's disease and their relation to age. Psychol Aging 2000;15:18-28.

42 SAS Institute Inc. SAS/STAT User's Guide, Version 8. Cary, NC: SAS Institute, 2000.

43 Peterson RC, Smith GE, Waring SC, et al. Mild cognitive impairment: clinical characterization and outcome. Arch Neurol 1999:56:303-8.

44 Ganguli M, Dodge HH, Shen C, et al. Mild cognitive impairment, amnestic type: an epidemiologic study. Neurology 2004;63:1 15-21.

45 American Psychiatric Association. Diagnostic and Statistical Manual of Mental Disorders, 4th ed. Washington, DC: American Psychiatric Association, 1994.

46 Du AT, Schuff N, Amend D, et al. Magnetic resonance imaging of the entorhinal cortex and hippocampus in mild cognitive impairment and Alzheimer's disease. J Neurol Neurosurg Psychiatry 2001;71:441-7.

47 Machulda MM, Ward HA, Borowski B, et al. Comparison of memory fMRI response among normal, $\mathrm{MCl}$, and Alzheimer's patients. Neurology 2003;61:500-6.

48 Wilson RS, Beckett LA, Bennett DA, et al. Change in cognitive function in older persons from a community population: relation to age and Alzheimer disease. Arch Neurol 1999;56:1274-9. 